\title{
Representações do jovem Anísio Teixeira sobre a Europa e suas escolas (1925)
}

Representations of Anísio Teixeira on

Europe and its schools (1925)

Representaciones del joven Anísio Teixeira sobre la

Europa y sus escuelas (1925)

José Geraldo Pedrosa

Centro Federal de Educação Tecnológica de Minas Gerais (Brasil)

https://orcid.org/0000-0002-8295-8313

http://lattes.cnpq.br/7103107947957772

igpedrosa@uol.com.br

Reisla Suelen de Oliveira Silva

Serviço Nacional de Aprendizagem Comercial (Brasil)

https://orcid.org/0000-0001-6870-4803

http://lattes.cnpq.br/1243667607200655

reislasuelen@yahoo.com.br

\section{RESUMO}

A inclinação definitiva de Anísio Teixeira pela educação pública amadureceu entre 1924 e 1929 quando uma série de experiências lhe sucedem, dentre as quais uma viagem à Europa (1925) tendo padres jesuítas como companhia. A questão do artigo é analisar o impacto que essa viagem, com duração de quatro meses, teria tido na inclinação definitiva de Teixeira para educação pública. $\mathrm{O}$ material empírico da pesquisa que deu origem ao artigo foi constituído por relatos pessoais produzidos por Anísio Teixeira durante a viagem e a partir dela. Representação social foi a referência conceitual e de método que norteou a pesquisa. Os estudos sobre representação social visam a identificar a representação do sujeito sobre algo, numa determinada circunstância ou contexto. Preocupou-se, portanto, em definir o que fosse o objeto de uma possível representação e, igualmente, em que circunstâncias sociais e culturais essa representação foi construída.

Palavras-chave: Anísio Teixeira; Representação Social; Europa e suas escolas. 


\begin{abstract}
The final inclination of Anísio Teixeira for public education has matured between 1924 and 1929 when a series of experiments succeed him, among which a trip to Europe (1925) with Jesuit priests as company. The question of the article is to analyze the impact that this trip, lasting four months, would have had on the final inclination of Teixeira to public education. The empirical material that led to the article was composed of personal reports produced by Anísio Teixeira during the trip and from it. Social representation was the conceptual and method reference that guided the research. Studies on social representation aim at identifying the representation of the subject about something in a particular circumstance or context. $\mathrm{He}$ worried therefore, in defining what was the object of a potential representation likewise in which social and cultural circumstances that representation was built.
\end{abstract}

Keywords: Anísio Teixeira; Social Representation; Europe and its schools

\title{
RESUMEN
}

La inclinación definitiva de Anísio Teixeira por la educación pública maduró entre 1924 y 1929 cuando una serie de experiencias le sucedieron, entre las cuales un viaje a Europa (1925) teniendo curas jesuitas como compañía. La cuestión del trabajo es analizar el impacto que ese viaje, de cuatro meses de duración, habrá tenido en la inclinación definitiva de Teixeira para la educación pública. El material empírico del estudio que dio origen al artículo fue constituido por relatos personales producidos por Anísio Teixeira durante y a partir del viaje. Representación social fue la referencia conceptual y de método que norteó el estudio. Los estudios sobre representación social buscan identificar la representación del sujeto sobre algo, en una determinada circunstancia o contexto. Fue, por lo tanto, una preocupación definir cuál sería el objeto de una posible representación e incluso en qué circunstancias sociales y culturales esa representación fue construida.

Palabras-clave: Anísio Teixeira; Representación social; Europa y sus escuelas. 


\section{INTRODUÇÃO}

Anísio Spínola Teixeira (1900-1971), pelo conjunto de sua obra como gestor, escritor e tradutor é um dos nomes mais importantes na história da educação brasileira. De acordo com Geribelo (1977), a bibliografia de Anísio Teixeira compreende um total de 268 publicações, incluindo livros, artigos de revistas e jornais, entrevistas, discursos, conferências, relatórios administrativos, prefácios, obras estrangeiras e traduções.

Essa condição faz com que a trajetória de Anísio Teixeira, seus escritos, projetos e intervenções educacionais seja objeto de muitas pesquisas e elaborações em forma de dissertações, teses e livros. Entre as biografias, a primeira foi publicada em 1960 para homenagear Anísio Teixeira em seu sexagésimo aniversário. O livro intitulado Anísio Teixeira: pensamento e ação foi organizado por Fernando de Azevedo (1960) e consiste numa coletânea escrita por treze eminentes intelectuais brasileiros: Gilberto Freyre, Afrânio Coutinho, Fernando de Azevedo, Darcy Ribeiro, Hermes Lima, Jaime de Abreu, Carneiro Leão, Juracy Silveira, Lourenço Filho, Gustavo Lessa, Luiz Henrique Dias Tavares, Delgado de Carvalho e Péricles Madureira de Pinho. Em 1973, dois anos após a morte de Anísio Teixeira, Hermano Gouveia Neto (1973), publicou o livro Anísio Teixeira: um educador singular. O livro foi fruto de exaustivo estudo sobre a vida e a obra de Teixeira, além de conter registros da homenagem que lhe fizeram na Bahia, por ocasião de seu septuagésimo aniversário. Wanda Pompéu Geribello (1977) publicou o livro intitulado Anísio Teixeira: análise e sistematização de sua obra. A autora entrelaçou dados biográficos de Teixeira, fazendo interface com seus escritos, projetos realizados e outras contribuições à educação. Em 1978, Hermes Lima publicou Anísio Teixeira: estadista da educação (LIMA, 1978). O livro descreve a trajetória do educador desde seu nascimento em Caetité (BA) até seus últimos projetos. Talvez pela ligação próxima que o autor possuía com Anísio Teixeira, a obra é mais do que um relato de vida, pois contempla aspectos bem particulares de Anísio Teixeira, antes não divulgados. Maria Lúcia Garcia Palhares Schaeffer (1988) publicou o livro intitulado Anísio Teixeira: formação e primeiras realizações, que enfatizou o progresso do pensamento educacional de Anísio Teixeira nos primeiros onze anos de sua vida pública - 1924 a 1935. Em 1990, Luís Viana Filho (2008) publicou o livro Anísio Teixeira: a polêmica da educação. $\mathrm{O}$ autor perpassou a vida de Anísio Teixeira desde o início de sua atuação pública na década de 1920, realçando detalhes de documentos, cartas e relatos de suas primeiras experiências educacionais. Clarice Nunes há muito se dedica ao estudo da vida e obra de Anísio Teixeira. Entre as publicações de Nunes a mais completa é intitulada Anísio Teixeira: poesia da ação (NUNES, 2000). Este livro foi publicado em parceria com o Centro de Documentação e Apoio à Pesquisa em História da Educação (CDAPH), na ocasião do centenário do nascimento de Anísio Teixeira. A autora investigou a trajetória de Anísio Teixeira, baseandose na ótica de atuação do historiador, recuperando fontes primárias de arquivos pessoais e estabelecendo diálogo com autores de outras biografias. Clarice Nunes também publicou em 2010, na Coleção Educadores, editada pelo Ministério da Educação, o livro Anísio Teixeira, que descreve resumidamente sua trajetória pela educação.

No que diz respeito às teses e dissertações sobre Anísio Teixeira, Darlene Olinda de Carvalho realizou, em 2012, levantamento no banco de dados da Coordenação de Aperfeiçoamento de Pessoal de Nível Superior (Capes). O relatório elaborado pela autora está presente no capítulo três da dissertação de mestrado intitulada Educação escolar $e$ americanismo em escritos de 1927 e 1934 de Anísio Teixeira. Os dados analisados compreendem o período de 1987 a 2011, tendo como referência a palavra-chave Anísio Teixeira. A autora encontrou 52 teses, 164 dissertações de mestrado acadêmico e doze produtos de mestrado profissional, totalizando 228 produtos. Entre os 228 produtos encontrados havia 133 pesquisas em que apareciam o nome de Anísio Teixeira, mas que não se referiam ao 
educador brasileiro e sua obra, mas, sim, ao Instituto Nacional de Educação Anísio Teixeira (Inep). Esses produtos sobre o Inep foram excluídos por Carvalho (2014) por não adotar a obra de Anísio Teixeira como objeto de estudo ou como referencial teórico. Após este primeiro filtro, permaneceram 32 teses e 63 dissertações de mestrado acadêmico, totalizando 95 produtos. Dos 95 produtos encontrados, a autora classificou-os em dois grandes grupos, sendo um o que Anísio Teixeira aparece como objeto de estudo (49 produtos) e outro como referencial teórico (46 produtos). ${ }^{1}$

Entretanto, o lugar de destaque de Anísio Teixeira na história da educação brasileira e a amplitude e profundidade de sua atuação e de seus escritos, fazem com que sua vida e obra ainda inspirem muitas indagações. Uma dessas questões é referente ao que teria conduzido Anísio Teixeira a inclinar-se definitivamente pela educação pública, já que os primeiros 25 anos de sua existência tendiam a conduzi-lo a outras atuações: padre, jurista, político ou administrador de latifúndio na Bahia. Em 1911 Anísio Teixeira entrou para o Colégio São Luiz Gonzaga, em Salvador, dirigido por padres jesuítas. Em 1914 passou a estudar no Colégio Antônio Vieira, da mesma ordem jesuíta. Da experiência nos colégios jesuítas nasceu o desejo de seguir carreira religiosa e, dos dezenove aos vinte e dois anos, Anísio Teixeira oscilou entre a vida consagrada e a vida secular. Nesse período cursava o segundo ano de direito, mas logo percebeu que não se identificava com a formação jurídica. Por outro lado, sentia forte influência familiar para que se conduzisse na direção da atuação política. Essa influência vinha de seu pai, Deocleciano, que tinha permanente ambição de que o jovem Anísio Teixeira se tornasse "(...) seu sucessor natural, futuro patriarca familiar" (NUNES, 2010, p. 14).

A inclinação definitiva de Anísio Teixeira pela educação pública amadureceu entre 1924 e 1929, quando uma série de experiências lhe sucedem: assume o cargo de inspetor-geral de ensino na Bahia (1924), viaja na companhia de padres jesuítas à Europa (1925), mergulha novamente nas questões educacionais baianas (1926-1927), viaja sozinho aos Estados Unidos da América-EUA (1927), retoma a gestão da educação baiana (1928) e, em 1928-29, retorna os EUA para cursar mestrado na Universidade da Columbia. Ao concluir esse conjunto intenso de experiências e retornar ao Brasil em 1929, Anísio Teixeira, com 29 anos de idade, já é definitivamente inclinado à educação pública para tornar-se um dos articuladores do movimento escola nova.

É nesse território que se situa a abordagem realizada no artigo. A questão mais geral é a de identificar, nesse conjunto de experiências realizadas entre 1924 e 1929, o que teria motivado o jovem Anísio Teixeira a inclinar-se definitivamente para a educação pública. A questão particular sobre a qual o artigo se dedica é a de identificar a importância, o peso ou a influência que a viagem com duração de quatro meses à Europa teria tido nessa inclinação definitiva de Anísio Teixeira pela educação pública. Afinal, essa é uma das questões sobre Anísio Teixeira que ainda permanece em aberto.

O material empírico da pesquisa que deu origem ao artigo foi constituído por relatos pessoais produzidos pelo jovem Anísio Teixeira durante a viagem realizada à Europa em $1925 \mathrm{e}$ partir dela. Tais relatos estão contidos em três textos. Um deles é uma entrevista que Anísio Teixeira concedeu ao jornal baiano A Tarde, em 30 de novembro de 1925, logo após o retorno da Europa. O segundo é um documento manuscrito de seis páginas, que contém anotações relativas às visitas de Anísio Teixeira às escolas da Bélgica, realizada por ocasião da mesma viagem de 1925. O terceiro e mais importante documento da viagem europeia é um conjunto de anotações manuscritas e pessoais feitas a bordo do navio, durante a viagem à Europa e a partir dela. Este último conjunto de anotações constitui o principal documento porque nele Anísio Teixeira descreveu o cotidiano da viagem e o conjunto de cenários e de cenas que ele registrou

\footnotetext{
${ }^{1}$ Para um exame detalhado das dissertações e teses sobre Anísio Teixeira recomendamos a leitura das dissertações de mestrado de Carvalho (2014) e Silva (2016).
} 
em sua mente para formar as representações do Velho Mundo. Os escritos acumulam 54 páginas, estando também o original sob guarda do CPDOC.

Representação social foi a referência conceitual e de método que norteou a pesquisa. Os estudos sobre representação social de Moscovici (2007) e Jodelet (2001) procuravam identificar a representação do sujeito sobre algo, numa determinada circunstância ou contexto. Preocupou-se, portanto, em definir o que fosse o objeto de uma possível representação e, igualmente, em que circunstâncias sociais e culturais essa representação foi construída. Neste sentido, buscou-se sempre considerar que o sujeito e jovem viajante Anísio Teixeira, além de brasileiro do início do século XX, era nordestino, filho de um coronel latifundiário e com forte formação católica jesuíta. Isso significa que a imagem ou a representação sobre a Europa e suas escolas certamente fora condicionada pela própria representação que Anísio Teixeira tinha do Brasil, um país predominantemente agrário, coronelista, atrasado economicamente e ainda marcado pela herança escravista.

\section{As circunstâncias da primeira viagem internacional de Anísio Teixeira}

Em 1925, Anísio Teixeira possuía apenas 25 anos de idade, acabara de formar-se em ciências jurídicas e de ser nomeado inspetor-geral de Ensino na Bahia. Deste contexto, surge a primeira questão: por que e para que o jovem inspetor de ensino vai viajar por quatro meses à Europa? Para esta questão os documentos pesquisados indicam uma combinação de motivos pessoais, justificativas políticas e religiosas.

Para o entendimento da ordem pessoal das motivações da viagem é oportuno antecipar algo que somente vai aparecer no relato da viagem aos EUA, realizada um ano e cinco meses mais tarde. Ao viajar aos EUA, em 1927, o jovem Anísio Teixeira afirmou que viajava em busca de juventude, rejuvenescimento. Ao viajar à Europa em 1925 o jovem Anísio Teixeira afirmou que precisava descansar. Parece que o jovem Anísio Teixeira, aos 25 anos, sentia-se cansado e velho, necessitando de novas fontes de energia e de inspiração. Estaria ele sentindo o fardo da formação jesuíta e familiar patriarcal? Pode ser que sim. Vale lembrar que os jesuítas investiam no recrutamento de Anísio Teixeira, isto é, tinham expectativas de que ele se consagrasse à vida religiosa. Ao mesmo tempo, Deocleciano, o pai de Anísio Teixeira, depositava muitas expectativas em sua atuação política. Tudo isso certamente era um peso para o jovem Anísio Teixeira. É por isso que em outra passagem deste artigo está afirmado que, aos 25 anos, Anísio Teixeira vivia num estado pessoal de tensões, insatisfações e contradições. Parecia demonstrar desconforto, mal-estar. Além disso, acabara de ser nomeado a um cargo público por puro prestígio político de seu pai. Prestígio que pode ser relativizado na medida em que o pleito do coronel Deocleciano era para ver Anísio Teixeira, recémformado em ciências jurídicas, ocupando a titularidade da pasta de assuntos jurídicos.

Para a surpresa de Deocleciano e de Anísio Teixeira, o governador Góes Calmon, recém-eleito, nomeou o jovem jurista para a pasta da instrução pública, isto é, para cuidar de escolas, professores e alunos. Veio daí a angústia que o jovem inspetor deve ter sentido: que fazer? Para esta pergunta, o jovem Anísio Teixeira não tinha respostas, embora soubesse da precariedade do quadro que enfrentaria. Não tinha respostas e nem onde buscá-las por perto. Para isso, ou seja, para a imensa tarefa que se colocava em sua agenda, era preciso descansar. Mas não era para descansar no sentido de descuidar-se; era descansar no sentido de renovarse, revigorar-se, encher-se de inspiração. Esse era, pois, o motivo pessoal da viagem: descanso, novas energias, inspiração. Se a Europa deu ao jovem Anísio Teixeira tudo aquilo que ele queria, é o que será pensado ao longo do artigo.

A justificativa política da viagem, de certo modo, era a menos relevante em 1925. Nessa época o Brasil já era uma república havia 36 anos, e governador certamente não tinha que dar muitas explicações acerca da ausência de quatro meses de seu inspetor de ensino. 
Além disso, Góes Calmon tinha elevadas expectativas com a atuação de Anísio Teixeira na Inspetoria de Ensino e sabia de sua inexperiência: era necessário possibilitar-lhe a formação necessária. Assim, a viagem, tinha um álibi escolar: Anísio Teixeira viajaria para visitar escolas.

Por fim, a justificativa religiosa, que, no Brasil católico de 1925, certamente era mais relevante que a justificativa técnica ou política. 1925 era o Ano Santo convocado pelo papa Pio XI e católicos de diferentes lugares estavam em peregrinação ao Vaticano. Anísio Teixeira viajou em companhia de autoridades eclesiais brasileiras. A propósito, na única entrevista que Anísio Teixeira deu ao jornal baiano A Tarde, o principal motivo que ele fez ecoar foi o de natureza religiosa, destacando o Ano Santo e a peregrinação ao Vaticano.

O jovem Anísio Teixeira parece ter realizado três roteiros na Europa: visitou igrejas e mosteiros (inclusive o Vaticano), visitou escolas (apenas na Bélgica e em Paris) e passeou pelas ruas de algumas cidades (de automóvel e a pé). O novato inspetor de ensino vivia um momento pessoal conturbado em decorrência da idade, dos desafios que tinha pela frente e dos conflitos existenciais de natureza política e religiosa. Nessas reflexões, que serão trazidas à tona em tópico específico, o jovem advogado manifestou sua formação cultural e inquietações típicas de um sujeito que demonstrava consciência e responsabilidade para com os problemas sociais brasileiros e as tarefas que lhe esperavam ao longo do século XX.

Sua formação intelectual e religiosa tradicional garantia-lhe traços marcantes como a organização e método na condução de suas coisas. Por isso, se Anísio Teixeira tivesse o intuito de divulgação de ideias e experiências da viagem à Europa, ele certamente levaria materiais necessários e disponíveis à época, entre tais, folhas de papel. O conjunto de notas que constituem o manuscrito de 54 páginas está numa escrita informal e fragmentada, as quais exigem paciência do leitor para decifrá-las. Há no documento muitas rasuras, algumas abreviaturas e palavras escritas em francês, inglês, alemão e espanhol.

É característica comum dos diários a sequência cronológica dos fatos datados. $\mathrm{Na}$ leitura desse conjunto de relatos pessoais de Anísio Teixeira, porém, percebe-se que não há registro diário dos acontecimentos. Há poucas datas indicadas para a autoria do escrito. A rigor, a associação do relato às datas é feita apenas para os acontecimentos de 17 de julho, relatado por Anísio Teixeira como o primeiro dia dentro do navio, e para os dias 11, 15, 16, 24, 28 e 29 de novembro, quando relatou suas passagens por Portugal, Espanha e França e, inversamente, no percurso de volta.

A falta de indicação das datas dificulta a compreensão sequencial dos fatos. No entanto, há registros de que a viagem durou cerca de quatro meses. Uma alternativa seria paginar o documento, facilitando consultas ou verificações das citações. Contudo pela falta de sequência cronológica do relato pessoal, optou-se por não numerar as páginas, atitude que poderia traduzir a ideia de que os escritos foram feitos em sintonia com a sucessão de acontecimentos e datas.

Alguns detalhes do texto contribuem para uma reconstrução do percurso geográfico realizado por Anísio Teixeira. Ademais, já de volta ao Brasil, em 30 de novembro de 1925, Anísio Teixeira concedeu a já referida entrevista ao jornal baiano A Tarde, relatando as impressões da viagem à Europa e sistematizando algumas representações sobre o Velho Mundo e suas escolas. Nessa entrevista ele mencionou o tempo de duração da viagem, suas visitas à Itália, França, Bélgica e ao papa Pio XI, que convocara os católicos em peregrinação do Ano Santo a Roma:

devo-lhe dizer que os meus quatro meses de ausência foram uma ronda ininterrompida pelos sítios mais delirantemente consagrados da inteligência e da literatura. (...) nos detenhamos em Roma, neste ano santo de 1925. (...) Quando tudo pregava o interesse, Roma pregava o 
desinteresse. E para dar o exemplo, abriu os salões do Vaticano para uma exposição que punha lágrimas nos olhos dos mais incrédulos. (...) Atravessamos as dezenas de salas do Vaticano (...) Na França, eu apenas trabalhei para fortificar as velhas admirações do meu espírito pela civilização e cultura francesa. Na Bélgica, as questões de ensino me absorveram por mais de vinte dias, em visitas cheias de interesse às escolas e institutos pedagógicos ${ }^{2}$. (TEIXEIRA, 1925b.)

É interessante notar, durante a entrevista, que Anísio Teixeira mencionou por uma vez apenas as escolas belgas, mas não se referiu às escolas francesas, mesmo havendo registro de que tenha passado por elas. Este depoimento talvez traga indícios da influência dos escritos do educador belga Omer Buyse, em seu livro Méthodes américaines d'éducation, que Anísio Teixeira havia lido antes da viagem à Europa. O jovem inspetor de Ensino certamente queria ver de perto os sistemas escolares do país de Buyse. Isso, sem contar o início das mudanças em seu pensamento educacional e revisão intelectual produzidas a partir dessa leitura, como afirma Shaeffer (1988). Para esta autora, o pensamento dualista que Anísio Teixeira possuía até então começou a diluir-se, mesmo antes de sua estada nos EUA. Shaeffer defende a ideia de que a leitura do livro do educador belga Omer Buyse, Méthodes américaines d'éducation, entre idos de 1924-1925, já produzira em Anísio Teixeira as primeiras mudanças acerca de suas concepções sobre educação e sociedade. Buyse "(...) lhe descortinava uma sociedade que surgia vitoriosa econômica e socialmente e, o que era mais grave, com uma grandiosidade que ameaçava a preponderância econômica do velho mundo europeu" (SHAEFFER, 1988, p. 15). A autora fundamenta sua assertiva ao comparar dois relatórios escritos por Anísio Teixeira antes e depois da leitura do referido texto de Buyse. O relatório produzido pelo educador e dirigido ao governador Goés Calmon em abril de 1925, antes da viagem à Europa, em muito se difere do primeiro e imaturo relatório produzido por ele em 1924, com o título "A propósito da escola única", quando Anísio Teixeira afirmava que a escola única seria simplória, inexequível e incapaz de desenvolver-se de forma igual para todos, tendo em vista a natureza desigual do homem. No relatório de 1925, Anísio Teixeira já propõe a reforma de ensino na Bahia, que seria aprovada poucos meses depois, deixa clara sua preocupação com o analfabetismo e critica a educação meramente livresca. Segundo ele, a educação deveria proporcionar aos alunos uma formação integral, desenvolvendo suas capacidades cívicas, morais, intelectuais e de ação. Outra medida destinada à promoção e à modernização do ensino, segundo Shaeffer (1988), foi a tradução e a distribuição do livro de Buyse aos professores baianos em 1927.

Anísio Teixeira abordou diversos assuntos nesse manuscrito mais extenso de viagem. Nas primeiras sete páginas ocupou-se em descrever o navio, o cotidiano de bordo, as pessoas que viajavam e o tratamento distinto que lhe era garantido no Sierra Morena, principalmente em decorrência das pessoas que o acompanhavam, ou seja, alguns figurões do clero católico.

Ao despertarmos no dia 17 de julho vagamos em pleno mar, resistindo o Sierra Morena de um modo admirável à inclemencia das ondas (...). Poderia citar, nesta viajem, toda uma extensa série de factos que confirmam essa asserção: desde a gentil solicitude de todo o pessoal de bordo, simplicidade do comandante a arranjar e colaborar

\footnotetext{
${ }^{2}$ Em todas as citações textuais será preservada a escrita original de Anísio Teixeira, que foi feita com as normas gramaticais de 1925. Essa transcrição literal inclui algumas palavras com erros gramaticais, expressões estrangeiras, abreviaturas e demais particularidades. Transcrever os trechos tal qual eles foram escritos é uma forma de preservar o caráter genuíno, pessoal e informal das anotações. Como já mencionado, ao escrever, Teixeira não revela nenhuma intenção de relatar para outros, ou seja, não escrevia para publicar.
} 
pessoalmente a todos os jogos e festas de bordo, até a atenção de ornamentar os salões com quadros sul-americanos, e (...) da língua hespanhola (...). Falava por grande parte do pessoal de bordo a tradução de carta de refeições em todas as línguas dos passageiros e mil outras pequenas cousas com que a companhia procurava tornar a viajem de cada um dos passageiros sem incidentes e sem contrariedades. (TEIXEIRA, 1925.)

Na sequência Anísio Teixeira descreve suas companhias de bordo e alguns eventos dos primeiros dias de viagem.

No primeiro domingo que passamos a bordo, celebrou-se, solenemente, a missa officiando S.Ex. Dom Mauvel - bispo de Ilhéos - e pregando em alemão e hespanhol. Dom Miguel Keuse, ilustre abade de S. Paulo. Várias vezes se tiraram fotographias de S.Ex. Dom Augusto já em grupo com os officiaes de comando do vapôr, já isolado, retratos que eram insistentemente procurados pelos passageiros. (...) Os jogos de bordo - observação sobre a simplicidade da raça - As festas de bordo - Canto - Dança - A vida de bordo. (TEIXEIRA, 1925.)

$\mathrm{O}$ texto prossegue entre narrativas sobre as paisagens naturais e urbanas, pelas observações acerca da cultura e sociedade europeias e algumas divagações sobre o sentido da vida, outras sobre política e outras ainda sobre o povo europeu. Percebe-se na escrita poética de Anísio Teixeira um encantamento pela cidade de Vigo, na Espanha, sua cultura, natureza e belas mulheres:

Mas, de Vigo a impressão realmente saudável e forte que trouxemos e não é de admirar desde que estavamos em terra de Espanha, foi a das suas mulheres (...) $\mathrm{O}$ asseio dos seus trajes vistosos, a insolencia de sua elegancia, o calôr dos seus olhos e de seu sangue, o vigor do seu trabalho, tudo constituia para a vista de extrangeiros avidos de impressões, um encanto salubre e rico. (TEIXEIRA, 1925.)

Influenciado pela bagagem sociocultural aristocrata que recebera, em ambiente ainda marcado pelos tempos do Império, Anísio Teixeira demonstrou saudosismo e afeição pelo regime monárquico em algumas partes de seus escritos, principalmente num relato de uma visita ao conde de Mafra, em Portugal. Anísio Teixeira reservou também algumas páginas à reflexão sobre a cidade de Paris, sua modernidade, encantos e desencantos. Paris, em 1925, certamente era um cenário de contradições. Por um lado ainda possuía resquícios da segunda metade do XIX, mas as consequências gerais da Primeira Guerra também compunham seu cenário. A despeito disso, a descrição de Paris é emblemática para o entendimento da representação que o jovem Anísio Teixeira trouxe da Europa, sua gente e sua cultura.

Além de motivos políticos, de descanso e peregrinação, a viagem tinha para Teixeira finalidade pedagógica, pois visitaria algumas escolas. No referido relato pessoal de seis folhas sobre as escolas europeias notam-se também improviso e ausência de sequência cronológica dos relatos, o que exige do leitor o mesmo esforço para montar a ordem dos fatos ou para compreender a sequência dos acontecimentos. Parte do relato pessoal de visita às escolas foi escrito em papel com as iniciais do hotel em que possivelmente Anísio Teixeira havia se hospedado: Hot 200 Chambers et appartements avec eau courante et salles de baim eletricite 
- Chuffage Central Ascenseur Lift Confort Moderne. A visita de Anísio Teixeira às escolas incluiu todas as séries de ensino.

Últimas visitas - Ás 8 horas a Escola Charles Buls. Immediatamente com Mr. Draps passei ao laboratório de psychologia experimental. (...) Fui depois a escola normal maternal - école normalegardienne - do estado para continuar minha visita do dia anterior. (...) Visitei o jardim de infância. Mto. Interessante. (TEIXEIRA, 1925).

Nas últimas páginas do relato principal de viagem, Anísio Teixeira produziu breve reflexão sobre sua estada na Europa, o aprendizado e as experiências adquiridas. Afirmou que o aprendizado foi curto, mas, importante do ponto de vista técnico. Mencionou também a sua fé e o ligeiro afastamento do campo religioso, ao qual se apegara até então. Finalmente encerrou a anotação, dizendo que havia muito trabalho na Inspetoria de Ensino da Bahia e que, apesar dos meses de elegante vagabundagem pela Europa, havia muito que se aproveitar, entretanto, “(...) está encerrado o ciclo de vida errante e amável” (TEIXEIRA, 1925).

\section{Impressões sobre o povo, cultura e paisagens naturais europeias: conflitos entre o velho e o novo}

Ao longo de sua viagem, Anísio Teixeira fez várias descrições sobre o povo, a cultura e as paisagens naturais europeias. Aparecem, no texto completo, sete vezes o adjetivo velho(as) para referir-se aos barcos, à cidade de Lisboa, a Portugal e a outras cenas ou cenários. A palavra novo(a) aparece por seis vezes para referir-se à Marinha Mercante alemã, às paisagens e aos conhecimentos adquiridos. $\mathrm{O}$ termo moderno $(a)$ foi mencionado por oito vezes para descrever o navio, as cidades ou o estilo de vida. Enfim, o vocábulo antigo $(a)$ foi referenciado por quatro vezes para descrever caminhos, um colégio e outras descrições casuais. O substantivo antiguidade foi utilizado uma vez para descrever um monumento visitado em Portugal.

Outro aspecto destacado por Anísio Teixeira sobre o povo espanhol, mais precisamente sobre as mulheres de Vigo, são as cores e a beleza que o remetem a um sentimento de familiaridade e encantamento, diferente do que descreveu sobre outros lugares que visitou na Europa.

Anísio Teixeira demonstrou certa insatisfação por ter passado tão rapidamente pelas terras da Espanha e também vestígios de proximidade com as mulheres de Vigo, uma vez que comenta que foi reconhecido por elas com uma saudável impressão de espiritualidade que lhe era própria. Adiante menciona os risos altos e a sadia beleza das espanholas. Por isso, apesar de Anísio Teixeira descrever que passara pela experiência os olhos apressados de viajante, nota-se, pelos detalhes, bastante intimidade e proximidade às mulheres espanholas.

Sobre o povo de Lisboa, as primeiras impressões de Anísio Teixeira não foram as melhores. Ao realizar comentário sobre os funcionários do mosteiro que visitara, houve percepção de grosseria e estranhamento de Anísio Teixeira com a cultura do lugar. A técnica, a impessoalidade e a formalidade dos europeus soaram-lhe como falta de educação. Essa é a representação típica do filho de um coronel latifundiário brasileiro, acostumado com a cordialidade e com o tratamento diferenciado dado aos seus. Tanto que, em seu relato pessoal, Anísio Teixeira (1925) grifou a palavra funcionários e desqualificou-os como: “(...) funcionários grosseiros e irritantes - todo aquele aspecto de repartição pública, em concertos, nos deixou a conviç̧ão material de como se está desfazendo a obra portugueza.". Nota-se que, ao demonstrar insatisfação pelo desfazimento da obra portuguesa, Anísio Teixeira novamente apresenta sintomas de apego ao conservadorismo. 
No percurso de volta, as belezas da paisagem do norte de Portugal e do Minho atraíram-no. Certamente sentindo o cansaço proveniente da viagem, Anísio Teixeira encontrou na paisagem do Minho uma pausa para seu corpo e mente afadigados:

(...) meu afadigado travessar da França, da Espanha e de Portugal encontrou no Porto e no Minho uma pausa de luminosa serenidade. (...) com a gente tradicionalmente simples e boa dessa região de Portugal enchiam-me o coração de frescura (...) Desembarquei vindo do Porto, ainda com os olhos cheios de delicadeza affectuosa da paisagem do Minho, paysagem de ouro e de azul que me encantou como uma pagina rara de literatura, na velha Lisbôa, foi uma triste manhã de chuva. (TEIXEIRA, 1925.)

Envolvido pela paisagem do Minho, o jovem Anísio Teixeira (1925), mais uma vez, referiu-se a Lisboa negativamente, dizendo que a "(...) velha cidade portuguesa não me dizia nada, depois que o Minho me presenteara com toda a frescura e todo o asul do país". Também não viu novidade no Porto, pois era uma cidade "(...) commercial apparentemente sem interesse". Nesse momento de tensão pessoal da vida de Anísio Teixeira (1925), o conservadorismo e estabilidade atraíram mais a sua atenção do que o dinamismo, por isso representou tão bem a paisagem do Minho, pois ela lhe transmitia a tranquilidade e o enraizamento de que seu espírito e mente precisavam. “(...) Tudo está tão enraizado, gente, e coisas, nessa terra do Minho que se traz de lá uma saudavel impressão de estabilidade, de segurança e de gosto".

Outro acontecimento relatado por Anísio Teixeira (1925) foi sobre uma visita a um amigo em Portugal: "A visita a um amigo ia povoar-me esse dia de Lisboa e o torná-lo para mim um dos mais inesquecíveis da viagem.", mas não esclareceu quem era esse amigo. Um fato considerável é que, num dado ponto da narrativa, ele reserva em torno de sete páginas para descrever uma visita ao conde de Mafra. A visita parece ter sido realizada no seu último dia em Portugal.

De volta ao Brasil! O meu ultimo dia de Europa passou-se na sombra de um dia de inverno em Lisbôa. Depois de soffrer as imposições de dois ou três chauffeurs, tomei um carro, com ares de limousine para casamentos, que me levou ao palacete do Conde de Mafra, por $30 \$ 00$. (TEIXEIRA, 1925).

A resistência aos ideais republicanos é evidente na escrita de Anísio Teixeira (1925) quando se refere à figura do conde de Mafra, dizendo que ele era "(...) uma figura de simplicidade e distinção incomparaveis. Homem de intelligencia e de coração a sua vida é hoje um culto interrompido as velhas e bôas cousas portuguesas banidas pela republica".

Ao descrever o palacete do conde de Mafra, Anísio Teixeira encantou-se com as recordações dos períodos idos de reinado e comparou-o a um servo da corte, tal qual os servos religiosos:

O seu palacete povoado de recordações de todos os reis da Europa e especialmente dessa côrte portuguesa de que ele foi um dos grandes servidores é bem o quadro de sua vida. A saudade impregna tudo, mas nada entristece. $\mathrm{O}$ seu piedoso culto por tudo que a sua intelligencia verdadeiramente aprecia e o seu coração verdadeiramente estima não entristece a sua vida, nem a faz sossobrar em uma inatividade 
reprovavel. Alegre, jovial ele vive corajosamente a sua dor, que aflora aqui e alli, na conversa, no olhar, no gesto, mas logo apagada por um sorriso, por um disfarce amavel com que accentia o digno e sobranceiro pudor de sua alma. (TEIXEIRA, 1925).

\section{3 À guisa de Paris}

O último dia de Anísio Teixeira em Paris foi 11 de novembro de 1925. No entanto, o relato que ele faz de suas representações sobre a capital francesa tem data de 24 de novembro, quando ele já se encontrava dentro do navio e de volta ao Brasil. Nesse sentido, o relato tem uma particularidade em relação às demais notas da viagem. De um modo geral as anotações são quase presenciais, isto é, os registros têm um sentido muito momentâneo e são feitos ora durante o ocorrido ou, no máximo, horas após, mas, em momentos próximos aos eventos observados. No caso de Paris, o relato e o registro das representações que ficaram cravadas na mente do jovem Anísio Teixeira foram feitos treze dias após aos acontecimentos, o que significa que as notas não tinham apenas o sentido de registrar o fato marcante, mas, de refletir sobre a própria experiência.

No registro de suas representações sobre Paris, Anísio Teixeira faz bem mais que descrever e produzir notas reflexivas. Ao longo do texto, o autor utiliza metáforas para descrever Paris, um dos ícones do Novo Mundo e da modernidade europeia. Paris foi lócus emblemático da revolução burguesa no século XVIII, das insurreições proletárias do século XIX, sinônimo de vanguarda, referência para a belle époque e para os otimismos iluministas e positivistas. Mas, em 1925, Paris já acumulava outras contradições, diferentes das do século XIX. Em 1925 haviam se passado apenas sete anos desde o fim da Primeira Grande Guerra e as marcas da destruição ainda estavam na paisagem urbana, assim como na alma dos parisienses. Tudo isso transpareceu no relato e nas ponderações do jovem Anísio Teixeira.

No início, a inflexão de Anísio Teixeira foi sobre a cultura europeia, sua visão desalentadora do ser humano a ponto de compará-lo a um condenado ao drama de seus dias:

O estado de espirito da humanidade hoje, nas grandes cidades é simelhante ao estado de espirito que costuma reinar na guerra. Um homem que esteja condenado ao drama formidavel e que faça a guerra com essa persuasão instintiva que é aquella a ultima cartada que elle joga, perde systematicamente a esperança. (TEIXEIRA, 1925).

Anísio Teixeira expressa uma ideia sombria acerca da humanidade moderna, sem perspectivas de futuro. Tudo isso parece sintoma de esgotamento e de incapacidade de renovar-se; ele percebia uma Paris velha e decadente, bem distante do que tinha sido até o século XIX, exuberante e triunfante. A figura do homem europeu também não difere na escrita do autor.

Ao descrever Paris, Anísio Teixeira comparou a vida na capital francesa a uma peça teatral, utilizando metáforas e palavras da língua francesa, como metteur en scène, para descrever suas impressões sobre a cidade. A descrição é sóbria e sem novidades, principalmente quando compara a cidade a:

(...) um filme singularmente confuso [...]. O real e o imaginario fazem um só par singularmente affectuoso, como na vida. $\mathrm{O}$ fantastico, o

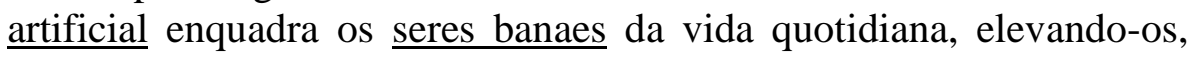
consagrando-os. As pequeninas maravilhas das mil e uma noites tem o 
aspecto de brinquedo de creanças à vista das realidades das grandes cidades de 1925. (TEIXEIRA, 1925). (Grifos nossos.)

No que se refere ao mapeamento da representação, são significativas as palavras que o jovem Anísio Teixeira escolhera para narrar e refletir sobre Paris. Na descrição de Anísio Teixeira, Paris era um filme, portanto, era algo da imagem e, não, da realidade; era um quadro inimaginável. Um filme é uma forma de representação da realidade e o jovem Anísio Teixeira referiu-se a Paris como uma representação. Mas Paris era um filme confuso, disperso, sem ordem, sem direção, sem rumo. Paris não era um sonho, era um pesadelo.

Anísio Teixeira (1925) compara Paris a uma Babel cosmopolita e, no meio das confusões de vozes, “(...) a naturalidade com que se extingue a luz em um cinema, é que a cidade toma todo o seu prestigio.". Em outra passagem o autor mencionou a noite parisiense, mas, não, a noite das casas noturnas ou das casas de espetáculo, mas, sim, a noite da cidade ou à noite na cidade. Ademais, na noite parisiense representada por Anísio Teixeira (1925) "(...) o chão é uma superfície movel de rodas e pes, que vão e vem, sobem e descem, riem, fonfonam, gritam numa apresentação supremamente original dos personagens". Paris é um “(...) ambiente requintadamente artificial (...) um studiogigantesco, em que já não houvesse a preocupação pueril de occultar os andaimes, os holophotes para a iluminação das scenas, e todas as pequeninas misérias dos bastidores e das coulisses (TEIXEIRA, 1925) (destaque do autor).

Na linguagem de Anísio Teixeira (1925), a noite de Paris é um delírio, quadro inimaginável da vida moderna e isso assustava o jovem jesuíta baiano. Nela "(...) passeia a alma decapitada e cega. Não o guia nenhuma força lucida. Não o guia nenhuma fortaleza.". Paris é irrequieta, sedutora, perigosa. Nela a "(...) matilha de todas as fraquezas e de todas as miserias envolve, morde, acua (...). Dentro do quadro dantesco da civilização o homem é um titere, grotesco como todos os titeres. Diverte-se. Diverte os outros. Chora. Comete todos os dramas.”. Nesse fantástico ambiente “(...) a maioria da humanidade dorme tranquilla ao lado da Allucinação. A curiosidade, o desejo, o fastio, o tédio, a attracção da miseria tecem a teia inverossimil e luminosamente arquejante do espectaculo de Paris" (TEIXEIRA, 1925).

A crítica de Anísio Teixeira (1925) à modernidade representada por Paris está em decorrência de sua confusão, falta de lucidez, falta de amparo em fortalezas. A Paris representada por ele é contraditória: combina alucinação e tédio. Tudo isso trouxe consequências que tornaram o indivíduo humano um títere, ou seja, um fantoche diante dos acontecimentos inexoráveis da metrópole. Mas isso ainda não é tudo que Anísio Teixeira (1925) anotou sobre sua representação de Paris. Lá, em 1925, a vida era um teatro, mas “(...) o numero de actores é sempre minusculo e o theatro, bem entendido, está vazio. Os actores representam para si mesmos.”. Nessa reflexão de natureza existencial, Anísio Teixeira afirmou que o homem passava pela existência representando uma peça teatral e sustentando máscaras, simulando os acontecimentos da vida para si mesmo, numa peça em que ele é apenas um ator coadjuvante, um fantoche que não tem controle e ânimo perante os acontecimentos.

Após a noite vem o dia, e “(...) quando o dia renasce moralizador, honesto, natural, sacudimos a cabeça suffocados como se acordassemos de um sonho de opio." (TEIXEIRA, 1925). Mas a euforia e o delírio não cessam em Paris. Noite após dia e dia após noite, o “(...) espetáculo (...) se repete em um só acto, e milhares de quadros pela décima milionésima vez. O sucesso é de tal ordem que se não espera mudança de cartaz” (TEIXEIRA, 1925).

\section{Visita às escolas europeias}

Já foi mencionado que Anísio Teixeira não descreveu em seu principal relato pessoal de viagem as visitas às escolas europeias, nem fez considerações sobre sistemas escolares. As 
exposições sobre educação, escola e sistema escolar estão em outro documento manuscrito de seis laudas, sendo quatro delas em folhas com pauta e duas em papel timbrado do hotel onde Anísio Teixeira provavelmente se hospedara. Há escritos no verso do papel que são ininteligíveis. Em decorrência das descontinuidades, certamente partes deste manuscrito foram perdidas.

Nesse documento Anísio Teixeira destacou um pouco as disciplinas observadas, o currículo, o método de ensino e a organização escolar; fez inflexão sobre alguns pontos positivos e negativos das escolas, contudo sem muito entusiasmo ou admiração. Parece que Anísio Teixeira não viu muitas novidades em relação ao que já tinha lido no livro de Buyse.

Em visita à Escola Charles Buls, Anísio Teixeira observou o laboratório de psicologia experimental durante duas horas e meia e analisou atividades desenvolvidas pelos alunos do último ano de estudo. Desta observação Anísio Teixeira (1924/1927) destacou que as experiências realizadas visavam a desenvolver os sentidos, a atenção e a memória, o que propiciavam ao aluno um “(...) o espírito de precisão e de escrúpulo a que conduzem naturalmente essas sutis investigações pedagógicas. Além disso, essas experiências abrem-lhe os olhos para a compreensão da pedagogia e sua atual preocupação científica". Nesse trecho Anísio Teixeira já antecipa as futuras proposições que faria sobre a educação escolar ativa, a confluência entre a ciência, cultura e prática.

Logo em seguida, Anísio Teixeira (1924/1927) relatou uma análise que fez dos “(...) trabalhos que os alumnos apresentam no fruir do último ano de estudo. Em sua consideração destaca o seguinte aspecto: "As theses ou melhor os assunptos são de preferência de sciencia pedagógica e tratados com o methodo, a clareza e a experimentação de um trabalho nitidamente scientifico".

Ainda na Escola Charles Buls, Anísio Teixeira observou também uma turma primária durante uma aula de geometria. É interessante notar como as observações realizadas pelo jovem Anísio Teixeira eram guiadas por um sentido prático, isto é, demonstravam ser observações dirigidas por uma consciência clara dos problemas que tinha para resolver como ocupante do cargo de inspetor de instrução pública na Bahia. Seu objetivo era identificar experiências significativas que podiam ser apropriadas em suas intervenções no Brasil. Desta observação sobre a aula de geometria, Anísio Teixeira (1924/1927) destacou os alunos que estudavam a superfície de um hexágono: “(...) fizeram o desenho geometrico trabalho manual, (recortaram figuras) e observaram a toda a licção foi assustavelmente concreta". É importante realçar as palavras e expressões que são empregadas no registro da observação: atividades, trabalhos práticos, trabalhos manuais, observação, atividades concretas. Dessa forma, na atividade observada, o que mais atraiu a atenção de Anísio Teixeira (1924/1927) foi a forma prática com que a aula era conduzida e “(...) o processo concreto, intuitivo e seguro com q o prof primário conduziu a sua aula de modo a fazer aquelas creanças comprehenderem a noção de superfície e o modo de medi-la.". É significativo o senso de pragmatismo expresso neste trecho, algo que permite pensar como o jovem de formação jesuítica já tinha uma sensibilidade para o pragmatismo, mesmo antes de conhecer a pedagogia de Dewey, algo que aconteceria mais tarde durante a viagem aos EUA. Mas tudo isso parece revelar o quanto as observações do jovem Anísio Teixeira também eram orientadas pela leitura do livro Méthodes américaines d'éducation. Ao mencionar a importância do aluno compreender o conceito e, logo após, praticá-lo ao medir a superfície da figura geométrica, Anísio Teixeira dá indícios de sua preocupação com a praticidade da educação e com a força da experiência e do uso dos sentidos na aprendizagem.

Na Escola Charles Buls, Anísio Teixeira assistiu também a uma aula de pedagogia para uma turma do primeiro ano de um curso de formação de professores. Mais uma vez, torna-se evidente o destaque que o jovem Anísio Teixeira dava ao caráter prático das atividades de ensino. 
Também na Bélgica, após visita à École Normale Gardienne, o jovem Anísio Teixeira citou a recente separação entre escola normal e o jardim de infância, dizendo que havia problemas e insuficiências neste modelo de ensino e muito o que se avançar. Na mesma escola, Anísio Teixeira evidenciou positivamente a condução do ensino às crianças, mencionando recursos didáticos como a música e o desenho, que são empregados de forma a atrair e manter a atenção dos alunos. Anísio Teixeira (1924/1927) grifou a palavra disciplina, deixando transparecer o método e a organização com que fora educado nos colégios jesuítas e a educação séria em que acreditava.

Sobre a gestão do sistema escolar Anísio Teixeira (1924/1927) fez referências às dificuldades burocráticas decorrentes de uma gestão centralizada: "O ministro é que decide tudo. [...] A directora lhes distribue o serviço, contratada pelas auctoridades do estado e pelo ministro, que diz sempre a ult a palavra." (TEIXEIRA, 1924/1927.)

Ainda na École Normale Gardienne, Anísio Teixeira (1924/1927) assistiu a duas lições sobre as quais não destacou nenhum aspecto particular, mas registrou interesse em manter intercâmbio e troca de experiências educacionais entre a Bélgica e o Brasil, a fim de implantar mudanças na educação brasileira: "Assisti ainda a uma licção de physica e outra de $(\ldots)^{3} \mathrm{e}$ conversamos depois valores e temas sobre o Brasil, a política, as directrizes sociaes do Brasil, etc. Fiquei de lhe enviar a legislação escolar do Brasil.".

Nota-se que neste relatório de seis páginas não há menção de Anísio Teixeira às escolas visitadas na França. Contudo, foram encontradas algumas correspondências no sitio eletrônico do CPDOC da FGV em que constam permissões para que o jovem inspetor visitasse as escolas francesas: como a carta de E. Orgeolet a Anísio Teixeira, pela qual se colocava à disposição para sua visita à École de le Dunoubs, em Paris. A referida carta está em papel com timbre do departamento de instrução primária: Préfecture Du Departament De La Seine. Direction de L'Enseignement Primaire Inspection (AT c 1925.10.05 Rolo 36 foto 565).

Há também uma segunda carta do diretor de ensino primário da França a Anísio Teixeira, pela qual lhe envia a lista das escolas primárias que poderiam ser visitadas em Paris. (AT c 1925.10.06 Rolo 36 foto 565).

Uma última carta veio do ministro de Ciências e Artes belga, pela qual autorizava Anísio Teixeira a visitar escolas primárias e maternais de Bruxelas na Bélgica (AT c 1925.10.21 Rolo 36 foto 569).

\section{Reflexões do jovem Anísio Teixeira, acerca de sua viagem à Europa: iluminando o espírito}

No relato pessoal principal da viagem à Europa, Anísio Teixeira escreveu cinco páginas nas quais fez uma autorreflexão para destacar as contribuições que sua primeira experiência internacional the proporcionara, tanto no âmbito pessoal, quanto intelectual e profissional. A primeira página da reflexão sobre a viagem tem data de 16 de novembro de 1925 ; as demais folhas não estão datadas. Também na entrevista ao jornal baiano A Tarde, de 30 de novembro de $1925^{4}$, Anísio Teixeira estabeleceu algumas reflexões sobre a viagem e aproveitou o ensejo para ratificar sua posição de católico fervoroso e saudosista da monarquia.

A matéria publicada no jornal inicia-se com o entrevistador, que pedia a Anísio Teixeira para resumir em apenas duas colunas suas impressões sobre a viagem. A reação ao limite sugerido pelo entrevistador revela a importância que Anísio Teixeira (1925b) atribuía à viagem e seu aspecto formador: “(...) resumir em duas colunas de jornal, se me torna a cabeça sonora como uma colmeia de abelhas, está muito longe de lhe dar a precisa tranquilidade para

\footnotetext{
${ }^{3}$ Expressão ilegível.

${ }^{4} \mathrm{~A}$ entrevista tem o seguinte título: "Paris é um filho espiritual de Roma".
} 
escrever e muito menos para resumir". Escreve ainda que as preocupações sobre os problemas de ensino que lhe tomaram o tempo nos últimos dias de viagem não seriam muito interessantes para serem discutidas num jornal “(...) desde que hoje, se não quisermos cair no impreciso de algumas considerações gerais, devemos, discutindo problemas pedagógicos, ferir profundamente a feição, dia a dia, mais técnica que assumem tais questões." (TEIXEIRA, 1925b). Afirmou também que os "(...) quatro meses de ausência foram uma ronda ininterrompida pelos sítios mais delirantemente consagrados da inteligência e da literatura" (TEIXEIRA, 1925b).

A impressão que se tem é que jornalista fez perguntas ao jovem Anísio Teixeira que as redigiu em forma de texto corrido; isso legitima o caráter pessoal da entrevista, pois a matéria não foi veiculada em forma de notícia, mas, sim, em forma de relato, colunas do jornal, o que se aproxima da mesma linguagem utilizada por Anísio Teixeira ao redigir os outros escritos sobre a viagem à Europa.

Logo na introdução da matéria, o jornalista faz uma menção importante sobre Anísio Teixeira. Ele utiliza-se dos adjetivos jovem e inteligente inspetor de Ensino para explicar sua viagem de peregrinação do Ano Santo e seu retorno à inspetoria para execução da reforma de ensino que fora assinada na Bahia. Destaca com veemência a imagem de religioso que Anísio Teixeira possuía. Essa imagem se comprova no decorrer da entrevista, pois o jovem fornece muitos detalhes sobre Roma, assuntos religiosos e monárquicos. Em nenhum momento Anísio Teixeira tratou com maior profundidade sobre Paris, Lisboa, Madrid, nem mesmo sobre as escolas belgas que visitara no fim da viagem.

A expressão peregrinação do Ano Santo, utilizada pelo jornalista, merece destaque. Anísio Teixeira, como jovem ligado à Igreja Católica, teve em sua viagem a companhia de autoridades eclesiais católicas, por isso se tem a impressão de que essa peregrinação fora algo como um álibi da viagem. A guerra deixara a Europa devastada fisicamente e desolada na alma, e o Ano Santo de 1925 parece ter sido uma iniciativa do Vaticano, visando a acalentar e animar o espírito das pessoas. Mas havia também um esforço em trazer os holofotes para Roma: “(...) a Igreja Católica teve em 1925, a sua mais formidável demonstração de força” (TEIXEIRA, 1925b). Outro fato é que a Itália passava por problemas políticos em 1925, como a segunda fase do governo de Mussolini e início da ditadura fascista. "E nos detenhamos em Roma, neste ano santo de 1925. O jubileu e a exposição missionária dominam com tal luz a vida da cidade cuja grandeza espiritual designou de eterna, que todos os outros problemas da Itália imergem na sombra." (TEIXEIRA, 1925b).

Em outra parte da entrevista Anísio Teixeira registrou por meio de algumas palavraschaves o quão desolada lhe pareceu a Europa pós-guerra, em 1925. Comparou a situação europeia semelhante a um cataclismo social, uma catástrofe em que não há saídas, a menos que as pessoas se voltassem ao Ano Santo e se rendessem à fé:

Ao se fechar o primeiro quartel de um século que prolongava a inquietude mental de uma humanidade desarticulada, na sua vida moral e espiritual, pelas correntes mais poderosas do erro e pelo mais profundo cataclismo social de todos os tempos, em que se julgou terem soçobrado todas as reservas de equilíbrio, de ordem e do sentido sobrenatural da vida, o Papa da sua cátedra de verdade fez um gesto paternal de convite: Todos os que colocavam acima das misérias as suas esperanças, viessem a Roma, numa manifestação de fé e numa manifestação de humildade, prestar a homenagem de seu coração e de sua inteligência à verdade salvadora do cristianismo. (TEIXEIRA, 1925b). (Grifos nossos). 
O Ano Santo de 1925 e a mobilização dos fiéis em peregrinação a Roma expressavam um esforço da Igreja Católica em fortalecer a autoridade do papa e firmar-se como referência:

Quando a marcha da civilização se faz, acentuadamente, no sentido material, numa época em que toda a cultura se volta para as coisas e deixa o homem, no seu sentido específico espiritual; que soberba e consoladora afirmação de humanismo fez o chefe espiritual da Igreja! (...) o Papa, durante todo um ano, a mão erguida em sinal de bênção, assistiu ao desfile daquela impressionante multidão de fiéis cuja demonstração me aparecia, no seio da nossa civilização mecânica e econômica, como um desses grandes gestos reparadores da humanidade, um desses momentos profundamente líricos e comoventes, que pensamos já não poderem florescer em nosso tempo, em que toda uma vida de erros se desfaz num instante de fulgor. (TEIXEIRA, 1925b).

Num trecho da mesma entrevista, Anísio Teixeira (1925b) afirmou que: "Ainda há tudo a sentir em uma Itália, mas já não há quase nada a dizer”. Esta afirmação é emblemática, pois de um lado Anísio Teixeira afirma que ainda não assimilara a viagem, isto é, não tinha elaborado em sua mente uma clara representação do que tivera como experiência. É como se a Europa estivesse sendo sentida por ele. Anísio Teixeira utiliza a palavra sentir, pois ela é da ordem dos sentidos e é pelos sentidos que o sujeito capta o mundo tangível e o carrega para si na forma de imagem mental. Por isso, ao afirmar que "(...) ainda há tudo a sentir em uma Itália”, Anísio Teixeira certifica que o objeto da experiência ainda não fora plenamente assimilado. Isso traduz certo espanto com a novidade europeia. Por outro lado, "já não há quase nada a dizer"; isso significa uma revitalização do espanto primeiro ou uma expressão de desencanto? A novidade europeia parece ter espantado o jovem Anísio Teixeira, mas, não, o encantado.

Mesmo tendo destinado em seu relato principal de viagem seis expressivas páginas para referir-se a Paris, Anísio Teixeira (1925b) introduz outras impressões sobre Paris muito diferentes daquelas utilizadas para mencionar Roma: "De Roma passando a Paris, porque não nos queremos deter senão nas grandes cidades intelectuais do mundo, eu me atrevo a dizer, sem paradoxo, que não é tão grande como se pode imaginar a distância transposta.". A modernidade do século XIX havia sido muito parisiense e a entrada em cena de Paris era uma afronta ao moralismo religioso, por isso o jovem, afeto à monarquia, sentiu desconforto em Paris. Nesses escritos enviados ao mesmo jornal, Anísio Teixeira representa Paris como forma de contraponto ao que acontecia em Roma, no Ano Santo de 1925. Nesse contraponto, o jovem Anísio Teixeira (1925b) exalta o caráter vanguardista de Paris: "Paris é a cidade das seduções inumeráveis, mas será preciso a profunda insanidade intelectual de certos viajantes para a julgarem, apenas, a cidade dos prazeres fáceis. A minha impressão pessoal hoje é que, Paris é um filho brilhante e genial de Roma.”. E qual era a relação umbilical entre Paris e Roma? O jovem Anísio Teixeira (1925b) via em Paris “(...) o maior acontecimento filosófico contemporâneo". E a qual era o acontecimento referido por Anísio Teixeira? Tratava-se do ressurgimento do pensamento monarquista:

Se o pensamento filosófico está hoje, com o declínio sensível de Bergson, dirigido pelo seu antigo discípulo Maritain, o pensamento político tem em França a sua mais forte afirmação em Maurras. Maurras, cujo grito de guerra - Polityque d'abord - faz dele, além de um dos maiores pensadores políticos mundiais, o homem do combate 
quotidiano, o jornalista que distribui, diariamente, pelo inumerável de seus leitores e discípulos, uma doutrina política forte, salubre, cheia de razão e de lógica. (TEIXEIRA, 1925b).

E Anísio Teixeira (1925b) previa o ressurgimento da monarquia com entusiasmo: "Paris movimenta toda uma mocidade intelectual profundamente sequiosa de se libertar das correntes poderosas do ceticismo, do racionalismo filosófico ou político.". Destaca também que a:

(...) reedição recente, quando estava em Paris, da sua formidável Enquête sur la Monarchie, teve um sucesso que se comparou ao do Contrato Social de Rousseau. Trinta mil exemplares se esgotaram em duas semanas. E a Enquête sur la Monarchie é um alentado volume de 20 francos e que está longe de ser uma obra de leitura popular. (TEIXEIRA, 1925b).

É perceptível em Anísio Teixeira, por meio dos filósofos e personalidade citados, que ele era, nessa época, afeto à monarquia.

Se a geração do último quartel do século XIX e começo do século XX intentou e concluiu o processo intelectual do século XVIII, cuja influência ainda se arrasta até nós, a tarefa e a responsabilidade da geração de hoje é a de refazer a obra doutrinária desfeita em 89. (TEIXEIRA, 1925b).

A propósito, as expressões utilizadas pelo jovem Anísio Teixeira (1925) permitem identificá-lo, stricto sensu, como um reacionário: “(...) a obra da reação é cada vez mais poderosa e mais brilhante em França.”. Anísio Teixeira (1925b) estava entusiasmado tanto com a incapacidade "do estado parlamentar de governar a França" e com os sinais de "queda do próprio regime, cuja agonia é sensível". Maior entusiasmo ainda era com as mobilizações restauradoras:

No dia em que deixei Paris, 11 de novembro, data do armistício, Philipe Barrès, Jacques d'Arthnis e Georges Vallois haviam convidado os franceses para uma grande reunião, onde se iam lançar as bases do Faisceau. (...) O Faisceau francês, como o fascio italiano, é um apelo a todas as velhas forças tradicionais da raça e do país e a sua mobilização em partido de guerra para a conquista das verdades essenciais de que nenhuma sociedade pode prescindir para viver. (TEIXEIRA, 1925b).

Raça, guerra e verdades: a linguagem do jovem Anísio Teixeira era inequívoca do ponto de vista de revelar suas preferências políticas:

Essas verdades essenciais, não julgue que evito o meu pensamento, essas verdades essenciais de autoridade, de ordem, de equilíbrio e de hierarquia se prendem indissoluvelmente às verdades religiosas e às verdades católicas e acolhem a Igreja como a mais benéfica das forças sociais. A idéia da França e a idéia do Catolicismo são idéias que não se podem separar na inteligência de uma grande parte da mocidade 
francesa e nos seus mais autorizados pensadores contemporâneos. (TEIXEIRA, 1925b).

Ao final da matéria, Anísio Teixeira (1925b) retorna à realidade baiana, dizendo que toda a discussão apresentada ao jornal os levaria muito longe, mas “(...) minhas responsabilidades sobre o ensino na Bahia são muito grandes, para que eu não concentre toda a atenção do meu espírito e todas as minhas energias na solução dos seus problemas.”.

Vale enfatizar que, no relato principal de viagem, Anísio Teixeira já havia revelado que a experiência em território europeu fora para ele uma maneira de conhecer melhor o mundo e assim melhor se conhecer e inserir-se nele. Em diferentes passagens do relato, Anísio Teixeira encontrava-se ainda muito enraizado em suas concepções de vida e, por isso, a viagem proporcionara-lhe o início de um desenraizamento que culminaria na renovação de seus pensamentos, e em inspiração para o enfrentamento da realidade que lhe esperava na inspetoria de ensino na Bahia. O trecho a seguir é indicativo de que Anísio Teixeira (1925) buscara por meio da viagem autoconhecimento e enriquecimento do sentido de vida: "Viajo, mais para descobrir e conhecer as terras alheias por onde vai passear a $\mathrm{m}^{\mathrm{a}}$ intell e o my coração, $\mathrm{p}^{\mathrm{a}}$. conhecer e descobrir os territórios inexploraveis do my espirito. Viajo, para enriquecer o meu sentido de vida.”. Para Anísio Teixeira (1925) viajar era semelhante a “(...) um "exercício espiritual”. É possível que esta analogia feita por ele se deva à influência de Santo Inácio de Loyola, padroeiro dos colégios jesuítas em que estudara. No livro deixado pelo santo católico, intitulado Exercícios espirituais, o exercício espiritual é um modo de exame da consciência, meditação, contemplação. É um meio de desenvolvimento espiritual. Certamente Anísio Teixeira almejava o desenvolvimento de seu espírito nessa viagem: fica evidente o caráter formador e de descoberta que viagem teve para o jovem Anísio Teixeira. Em outra passagem Anísio Teixeira manifesta as expectativas que ele tinha da viagem.

(...) que eu percorrer seras, apenas, os estimulos de minhas intimas descobertas. Debruçado sobre as naçoes de todo o mundo, cheio de solicitude, de simpatia e de benev. presença, extrairei os desvios do my espirito, acolhendo os ensinamentos que se desprendem de cada terra e de cada povo. Um extrang assim surprehendido é um professor e um mestre, a cuja sombra, uma vez, nos transformamos. Um novo conhecimento, uma nova aff. espiritual descoberta e alimentada é um excitante para aquelas misteriosas explor. em nosso mundo interior. (TEIXEIRA, 1925).

Quando Anísio Teixeira menciona as expressões mundo interior e íntimas descobertas, dá a ideia de busca por autoconhecimento e amadurecimento de identidade. Ele se compara a um aluno sempre disposto a aprender. Outra expressão significativa é, mais uma vez, o sentido de amadurecimento espiritual que Anísio Teixeira confere à viagem ao dizer que extrairá os desvios do seu espírito. Estaria o espírito e intelectualidade de Teixeira em mudança de direção? Estaria o jovem Anísio Teixeira em conflitos com sua formação jesuítica e sua simpatia com a monarquia?

O tempo verbal utilizado pelo autor traz um ponto de dúvida. Nas partes referenciadas, Anísio Teixeira parece escrever antes de a viagem acontecer, pois menciona mais expectativas. No texto a seguir, porém, Anísio Teixeira expressa sentimento de gratidão pelo que a viagem proporcionou ao seu sentido de vida. 
Nessa pag. de alb em que a Srta. me pede para deixar o myautogr, deixo tambem a expressão o agradecimento consumido pelo que concorreu afim de enriquecer o meu sentido de vida quero, tambem, exprimir o quanto sou reconhecido pelo que a Senhorita tenha concorrido para enriquecer o meu sentido espiritual de vida. (TEIXEIRA, 1925)..

Nota-se que a palavra enriquecer é repetida por duas vezes neste pequeno trecho. O verbo parece manifestar o movimento intelectual feito por Anísio Teixeira por meio da viagem, que se deu no sentido de buscar soluções às suas tensões vocacionais, profissionais e inspiração para os novos desafios na Inspetoria de Ensino. Também para fornecer-lhe respostas para a "(...) crise de consciência entre os deveres para com Deus e os deveres para com o homem" pelos quais ele passava antes de seguir para a Europa, em 1925 (LIMA, 1978, p. 60). No entanto, mais que respostas a viagem lhe parece ter trazido questionamentos que lhe serviram como molas propulsoras para suas novas experiências e novas leituras que culminariam em sua primeira viagem aos EUA.

Sobre os ganhos do ponto de vista técnico que a viagem à Europa lhe proporcionara, Anísio Teixeira (1925) questionou: "Até que ponto os meus desejos e as minhas previsões se realizaram? De "(...) modo geral devo dizer que o aprendizado foi muito curto e que é muito cêdo para tirar conclusões.". As expressões são significativas e antagônicas: por qual motivo o aprendizado fora curto? Seria em virtude de seu longo e intermitente desejo de aprender? Ou a Europa não lhe trouxera grandes inspirações? Ou, ainda, teria Anísio Teixeira feito apropriações apressadas sobre a viagem a ponto de não ter elaborado tudo que gostaria de registrar nesse manuscrito? Esta última possibilidade parece não sustentar-se, pois, se a viagem tivesse para Anísio Teixeira um caráter extraordinário, certamente ele o manifestaria mais tarde, assim como fez nos seus escritos dos EUA. Pode ser que ainda fosse cedo para tirar conclusões, mas as expressões indicam também que a Europa pode ter parecido velha demais aos olhos do jovem Anísio Teixeira e, por isso, pouco inspiradora, pouco motivadora, pouco encantadora. Ao afirmar que viagem fora longa e o aprendizado curto, ganha força a ideia de que os países europeus não tinham muito a oferecer ao jovem Anísio Teixeira do ponto de vista de sua renovação espiritual. Ávido por novos conhecimentos, Anísio Teixeira enfatizou que a viagem à Europa não atingira todas as suas expectativas e, no quesito fé, sua expressão parecia estar cada vez mais distante do seu antigo ideário de católico fervoroso. Por isso afirmou que a certeza e a "(...) compreensão metaphysica da vida não está também cada vez mais afastada de mim, como um objeto que eu conservo o culto mas de que já não uso? Não foi essa viagem talvez outra cousa sinão uma dissipação do espirito e da intelligencia." (TEIXEIRA, 1925).

Anísio Teixeira repetiu por três vezes em toda esta parte do relato, a palavra espiritual e oito vezes a palavra espírito, isso revela o quanto a viagem abalara suas certezas acerca da existência, bem como suas antigas concepções religiosas.

Sob o lado techinico ganhei evidentemente alguns conhecimentos novos. Sob o lado de formação geral augmentei, é inegável, o meu cabedal de cultura.Mas, a minha resposta sobre a influencia dessa viagem sobre a qualidade do meu espirito, será tão positiva?Se posso dizer que ganhei mais facilidade diante da vida, não deverei dizer que ganhei mais banalidade diante da existencia? (TEIXEIRA, 1925).. (Grifos nossos) 
A palavra qualidade é destacada por Anísio Teixeira, que se questiona sobre a situação do seu espírito, que parece enfraquecer-se e desinteressar-se pelas questões dogmáticas, ganhando assim mais materialidade, característica que já compunha sua personalidade, mas, que estava ofuscada por seu idealismo. Para ele, seu “(...) espirito dissipou-se na sua fé. A intelligencia diluiu ainda mais a sua cultura." (TEIXEIRA, 1925). Os novos conhecimentos iluminavam sua razão, mas, por outro lado, relutava em permanecer enraizado em suas verdades e crenças. "Ah! Como seria melhor do que essa vaidade de enriquecer o espirito com viagens e com espetáculos deslumbrantes e novos, possuir o amor tranquilo e algumas cousas certas e profundamente enraizadas." (TEIXEIRA, 1925).

Decerto Anísio Teixeira (1925) se sentia desconfortável com os rumos os quais seus pensamentos tomaram e, diante das tarefas que lhe esperavam na Inspetoria de Ensino, refletiu que sua passagem pela Europa foram “(...) quatro meses de elegante vagabundagem”, mais adiante em seu relato, admitiu, apesar disso, que havia muito a se aproveitar:

Desses quatro meses muita cousa se há de aproveitar. Mas está encerrado o ciclo da vida errante e amável. Vamos trabalhar e pensar. E nos vagares das nossas pausas ouçamos, como um velho ouve um moço descuidado, as aventuras de nossa viagem, para tirarmos delas conclusões práticas e sizudas. (TEIXEIRA, 1925).

A pouca novidade diante da cultura e escolas europeias, de forma alguma enfraqueceram o desejo de Anísio Teixeira em trazer ao Brasil soluções educacionais que dessem conta dos problemas enfrentados na época, bem como respostas concretas à sua atuação na Inspetoria de Ensino.

\section{Considerações finais}

Acostumado com a cena baiana - clima quente e seco, cidades mal iluminadas, sem infraestrutura e serviços e muita pobreza social -, é evidente que o jovem Anísio Teixeira se sentiu impactado pela Europa, onde sentiu o frio que nunca havia experimentado, se deparou com a neve, contemplou Paris e sua noite iluminada, conversou com pessoas e visitou lugares representativos da civilização europeia.

Entretanto, a despeito do choque cultural e civilizacional, Anísio Teixeira viu pouco, talvez nada, de inédito ou de encantador na Europa. A Europa não entusiasmou nem inspirou Anísio Teixeira, que pertencia a um círculo familiar latifundiário e coronelista e convivia com pessoas cultas de origem europeia, principalmente figuras ligadas ao clero. Apesar de nunca ter ido à Europa, o jovem Anísio Teixeira certamente tinha acesso a relatos pessoais sobre como eram as paisagens e as pessoas europeias. Ou seja, Anísio Teixeira tinha uma representação prévia da Europa e é em relação a esta representação que a experiência concreta parece não lhe ter soado como inédita.

Mas ter uma representação já elaborada no Brasil sobre a Europa não significa que o jovem Anísio Teixeira tivesse muitas e elevadas expectativas em relação à Europa. A demonstração dessa ausência de elevadas expectativas é que Anísio Teixeira não se preparara para a viagem. Para a educação escolar o único guia que Anísio Teixeira levara era o livro de Buyse sobre as escolas belgas que aplicavam métodos americanos. Fora isso, Anísio Teixeira não levara consigo um conjunto de questões bem definidas a serem observadas e relatadas. Talvez até mesmo o roteiro de viagem, com exceção da Bélgica, não tenha sido definido por ele, mas, sim, pelas companhias clericais, que, inclusive, o ciceronearam durante boa parte da viagem. A sensação é de que a representação após viagem não tinha nada de novo em relação 
à representação que Anísio Teixeira já possuía sobre a Europa e que fora elaborada em conversas com figuras do clero que conheciam a Europa.

A propósito, quando Anísio Teixeira emprega expressões que designam um estado espiritual de surpresa em relação ao que vira na Europa, tais expressões designam surpresas negativas. Em diferentes aspectos a Europa aparece na sua representação como um mundo velho e sem futuro. Em nenhuma passagem faz menções à democracia política e social, ao movimento e ao dinamismo do cotidiano ou à mobilidade e à igualdade nas relações sociais. Além de velha, a Europa não estimulou nem inspirou o jovem Anísio Teixeira, recémempossado inspetor do ensino público na Bahia. A descrição da representação negativa de Anísio Teixeira sobre Paris é emblemática. A cena parisiense representada por Anísio Teixeira é a de um mundo espetacularmente superficial e inconsistente.

Se a velha Europa não apareceu como inédita, nem encantou, inspirou ou entusiasmou o jovem baiano, o mesmo pode ser afirmado em relação às escolas europeias. O jovem inspetor esteve em Portugal, Espanha, França, Itália e Bélgica. Mas as visitas dirigidas de cunho estritamente escolar foram registradas somente na Bélgica, onde o jovem Anísio Teixeira queria ver métodos americanos em prática. Nas escolas belgas Anísio Teixeira não viu nada além do que já estava no livro de Omer Buyse, que lhe fora dado por Carneiro Leão, quando fora nomeado para a Inspetoria da Instrução Pública. Já foi mencionado que a visita às escolas belgas resultou num relato manuscrito de apenas seis páginas, o que significa que Anísio Teixeira pouco anotou além do que já constava no livro sobre métodos americanos de educação.

Essa representação pouco ou nada inspirada que Anísio Teixeira elaborou sobre a Europa e suas escolas parecem ter diferentes sentidos ou motivos. Por um lado, a Europa de 1925 ainda tinha em sua fisionomia marcas expostas da Primeira Grande Guerra, que acabara seis anos antes da sua viagem. Essas marcas expostas da Primeira Guerra estavam nas paisagens urbanas e na vida social: guerras destroem e reconstruções geram sacrifícios sociais.

No que diz respeito à educação e às escolas europeias, algo condicionante da representação pouco inspirada ou desprovida de encantos vinha do envolvimento ainda incipiente do jovem Anísio Teixeira com as questões educacionais. Certamente não foi em 1924, quando o governador Góes Calmon o nomeou para a pasta da instrução pública, que Anísio Teixeira decidira inclinar-se definitivamente para a educação, assim como não tinha uma elaboração tão profunda dos problemas escolares públicos que ele tinha pela frente. Recém-formado em ciências jurídicas e sociais, incipiente e chegado abruptamente à educação, o sujeito que viajara à Europa ainda não era uma pessoa decidida a inclinar-se à educação. Se Anísio Teixeira não foi à Europa já decido a dedicar-se à educação, o mesmo pode ser dito do sujeito que regressa da Europa. Não foi a Europa e suas escolas que despertaram em Teixeira a inclinação pela educação. A despeito do impacto cultural e civilizacional proporcionado pela viagem, Anísio Teixeira viu pouco, talvez nada, de inédito, de entusiástico ou de encantador na velha Europa.

\section{REFERÊNCIAS}

AZEVEDO, Fernando et al. Anísio Teixeira: pensamento e ação. Rio de Janeiro: Civilização Brasileira, 1960.

CARVALHO, Darlene Orlinda Costa de. Educação escolar e americanismo em escritos de 1927 e 1934 de Anísio Teixeira. Belo Horizonte: Cefet, 2014. 101 p. (Dissertação) Mestrado em Educação Tecnológica, Centro Federal de Educação Tecnológica de Minas Gerais, Minas Gerais, 2014. https://doi.org/10.14295/2596-2221.xviceel.2018.139

GERIBELO, Wanda Pompeu. Anísio Teixeira: análise e sistematização de sua obra. São Paulo: Atlas, 1977. 
GOUVEIA NETO, Hermano. Anísio Teixeira - educador singular. São Paulo: Companhia Editora Nacional, 1973.

JODELET, Denise. Representações sociais: um domínio em expansão. In: JODELET, Denise (Org. ${ }^{\text {a }) . ~ A s ~ r e p r e s e n t a c ̧ o ̃ e s ~ s o c i a i s . ~ R i o ~ d e ~ J a n e i r o: ~ E d . ~ U e r j, ~} 2001$. https://doi.org/10.17771/pucrio.acad.16772

LIMA, Hermes. Anísio Teixeira: estadista da educação. Rio de Janeiro: Civilização Brasileira, 1978.

MOSCOVICI, Serge. As representações sociais: investigações em psicologia social. Tradução de Pedrinho Guareschi. 5. ed. Petrópolis: Vozes, 2007. https://doi.org/10.5212/praxeduc.v.6i2.0013

NUNES, Clarice. Anísio Teixeira: a poesia da ação. Bragança Paulista: Edusf, 2000.

NUNES, Clarice. Anísio Teixeira. Recife: Fundação Joaquim Nabuco / Ed. Massangana, 2010.

SCHAEFFER, Maria Lúcia Garcia Pallares. Anísio Teixeira: formação e primeiras realizações. São Paulo: USP/Faculdade de Educação, 1988.

SILVA, Reisla Suelen de Oliveira. Representações sobre Europa e América e suas escolas: comparação entre os escritos de viagens do jovem Anísio Teixeira (1925-1927). Belo Horizonte: Cefet, 2016. 139 p. (Dissertação) Mestrado em Educação Tecnológica, Centro Federal de Educação Tecnológica de Minas Gerais, Minas Gerais, 2016. https://doi.org/10.14295/25962221.xviceel.2018.139

VIANA FILHO, Luís. Anísio Teixeira: a polêmica da educação. 3. ed. São Paulo: Unesp / Salvador: Edufba, 2008.

\section{Fontes primárias}

TEIXEIRA, Anísio. Anotações de viagem à Europa. Lisboa, 1925, 54 p. Atpi: 25.07.17 (filme 03). FGV/CPDOC.

TEIXEIRA, Anísio. Anotações relativas às escolas europeias quando de sua viagem de estudos. Europa, 1924/1927, 6 p. Atpi: 1924/1927 (filme 03). FGV/CPDOC.

TEIXEIRA, Anísio. Paris é um filho espiritual de Roma. Entrevista. A Tarde. Salvador, 30 nov. 1925b. Disponível em: <http://www.bvanisioteixeira.ufba.br/artigos/paris.htm>. Acesso em: 3 maio 2015. 